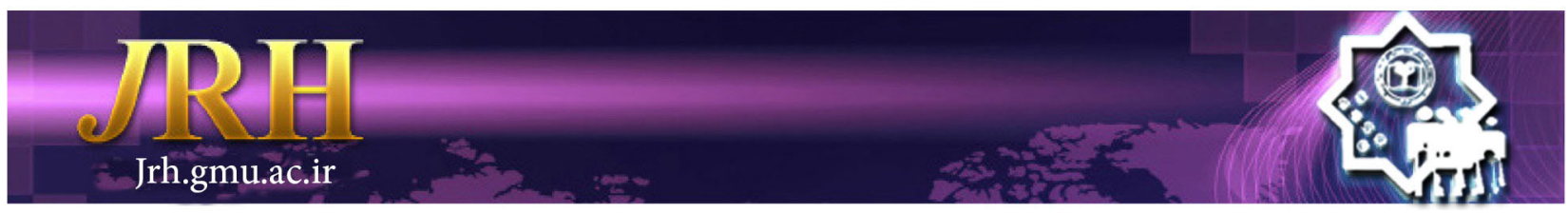

\title{
A comparison of graphic characteristics of drawing a family, attachment disorders, and parental parenting styles in anxious and normal girl children
}

Mahnaz Sheikh ${ }^{1}$, Mahvash Raghibi ${ }^{2}$, Hanieh Sheikh ${ }^{1}$

\author{
Journal of Research \& Health \\ Social Development \& Health Promotion \\ Research Center \\ Vol. 9, No. 5, Sep \& Oct 2019 \\ Pages: $418-427$ \\ DOI: $10.29252 / j$ rh. 9.5.418 \\ Original Article
}

1. Department of Psychology, Faculty of Psychology, Islamic Azad University, Zahedan Branch, Iran

2. Department of Psychology, Faculty of Psychology and Educational Psychology, University of Sistan and Bluchestan, Zahedan, Iran

Correspondence to: Mahnaz Sheikh, Department of Psychology, Faculty of Psychology, Islamic Azad University, Zahedan Branch, Iran

Email: Sheikh.mahnaz@yahoo.com

Received: 26 Nov 2016

Accepted: 3 Dec 2017

How to cite this article: Sheikh M, Raghibi M, Sheikh H. A comparison of graphic characteristics of drawing a family, attachment disorders, and parental parenting styles in anxious and normal girl children. $J$ Research Health2019; 9(5): 418- 427.

\begin{abstract}
Anxiety is the most prevalent psychiatric disorder in childhood which affects various aspects of children's lives. This study aimed to compare graphic characteristics of drawing a family, attachment disorders, and parental parenting styles in anxious and normal girl children. This was a causal-comparative study. Its statistical population included all girl children aged 5 to 8 years old who were studying in kindergartens and elementary schools of Zahedan in 2015-16 and their parents. 50 children with anxiety disorders and 50 normal children were randomly selected as the sample. The tools were the Baumrind parenting style test, the Randolph attachment disorder questionnaire, and the draw-a-family Test. The data were analyzed by the chi-square and multivariate analysis of variance and the graphical characteristics of the children's drawings were evaluated using the draw-a-family test. The results indicated that considering the graphic characteristics of the children's drawings, there was a significant difference between the anxious and normal children and with regard to attachment disorders, there was a significant difference in terms of bullying at 0.99 confidence level. No significant difference was found between the anxious and normal children considering their parents' parenting styles. Overall, it can be inferred that drawing a family can be used as a proper method to detect children's family and emotional issues and to protect them from mental disorders.
\end{abstract}

Keywords: Attachment Disorder, Family, Parenting

\section{Introduction}

Anxiety is the most prevalent psychiatric disorder in childhood. Since children, due to their age, are not able to deal with and overcome this phenomenon, anxiety in children is more serious and dangerous than that in adulthood. Thus, in childhood, anxiety disrupts academic achievement, social adjustment, family life, and relations with peers [1]. Anxiety involves the concept of insecurity or threat, the source of which is not clear to a person and it is assumed that the person is incapable of controlling it [2]. Although biological, psychological, and social factors play effective roles in the etiology of anxiety disorders, environmental factors play prominent roles as well. The prevalence of anxiety disorders in childhood and early adolescence is estimated to be about $10 \%$ and this prevalence rate gets an upward 
trend as people get older. Moreover, anxiety is more prevalent among girls compared to boys [1]. Nowadays, among attempts made to aid people to perceive mental life, emotional developments, and why mental disorders occur in children, theories that consider the motherchild relationship, also known as attachment, as a core concept have attracted a lot of attention [2]. Freud, for the first time, stated that a newborn's emotional bond with his/her mother is the basis of all subsequent relationships [3]. In this regard, some researchers noted that many forms of mental and personality disorders are the result of depriving a child of maternal care or lack of stability in the relationship of the child with his/her attachment figure [4]. A mother has an undeniable impact on the emotional development of her child. On one hand, through establishing good relationships, she can aid the child to be normal and fully developed and on the other hand, in the case of destructing their relationships, she can lead her child to a variety of mental disorders followed by all kinds of psychological suffering. This is why attachment is regarded as the essential element of natural evolution [5] and facilitates the expansion of abilities to cope with stress in new situations [4].

As mentioned by Gimpel and Holland, emotional developments and cognitive skills have been used to regulate emotions are deeply linked with relations between a child and his/ her parents, especially his/her mother [6]. In the same line, another study confirmed the impact of the quality of attachment on children's development and showed that children who do not have a proper pattern of attachment are often nervous, militant, and antisocial and they turn into parents who are not able to establish good and stable relationships with their children [7]. In alignment with this study, Kamijani mentioned that children who are rejected by their attachment figures are likely to feel intense loneliness, be anxious and angry, and have low self-esteem [8].

Moreover, it is quite obvious that studying child development regardless of cultural patterns and parenting styles is deficient. A family is the first place where a child's personality, values, and intellectual standards would be formed. Additionally, a family plays a key role in determining a child's lifestyle. During the development of a child, the environment of a family can act as a positive factor which provides the ground for the child's growth or can play a role as a disruptive factor. Meanwhile, the systems of upbringing children in families, also known as parental parenting styles can be considered as the most important factor affecting the character formation of a child [9].

Parenting styles can be regarded as a set of behaviors that describe the child-parent relationships over a wide range of situations [10]. In most cases, lack of parental attention to keeping the mental and emotional environment of a child healthy and lack of establishing proper relations lead to emotional deficiencies [11]. Stressful situations in life and workplace, socioeconomic status, culture, and parental attitudes towards their child's rearing all affect the parent-child relationships [12]. Accordingly, applying inappropriate parenting practices leads to emotional and attachment disorders among children [13]. Parents who disagree on method of raising their children use a rejecting or dominant parenting style, do not believe in stable moral standards, and seek perfection unreasonably and those who are precarious, unassured, unstable, angry, and emotionally unstable make their children be emotionally in need and deprive them of confidence and security that are the basis of healthy emotional development [14].

The results of Faramarzi, Taghipoorjavan, Dehghani, and Moradi demonstrated that parents' behaviors in relation to their children significantly impact them [10]. Additionally, another study carried out to examine the relationship between children's mood and maternal parenting attitudes concluded that maternal strict disciplinary practices expand negative emotions and social development of children [11]. Evidence indicated that the authoritative parenting style has a positive impact on children and the permissive and 
authoritarian parenting styles have negative effects on them [15].

On the other hand, when children grow in families that neglect them, they grow in unhealthy way and are likely to have negative beliefs [16]. Therefore, the issue of children's mental health is one of the most important concerns of life [17]. Since, on one hand, various emotional disorders are associated with the construction of a family system and they are, on the other hand, is related with a child's perception of his/her family, it seems that conducting simple interviews with a child do not show his/her true feelings towards his/her family. Children are fully aware of adults' explanatory purposes; therefore, drawing a family can be considered as the best tool to detect a child's issues [18].

In addition to individual characteristics of a subject, the Draw-A-Family (DAF) test reflects his/her family relations and needs, many conflicts and unconscious tendencies, defensive mechanisms, and personality disorders. This test aids a therapist to establish good relationships with a client in order to aid him/her solve his/ her problems [19]. Other words, a child draws the surrounding world not as it is but as he/she explores it within his/her limited mentality and logic [20]. Researchers believe that drawings display various aspects of a child's personality which are more permanent and stable than the transient emotional states. Dadsetan, Buck, put an emphasis on the necessity of comparing the obtained graphical data with the history of a subject's life [21]. In addition, conducting this test on a group of children indicated that children draw their parents taller and bigger than other men and women even when the details are equal [22]. As mentioned in a study, the symptoms of emotional difficulties and lack of stability and security can be diagnosed in a child's drawing by focusing on hostile images, unrecognizable shapes and drawing animals, forms suspended in the paper, and drawing people in a distance [23].

According to what was mentioned earlier, the mutual parent-child relationship (attachment) and parenting styles are regarded as the core concepts of child psychopathology topics and problems in these areas can be considered as risk factors [24]. The importance of this issue becomes clear when considering these children as future parents who through their emotional reactions towards their children may create attachment disorders in them. Due to being accompanied with aggressive and violent behaviors, these disorders may widely bring harm to the society [25]. In this regard, these children can be distinguished from other children through knowing their issues and specific characteristics. Moreover, providing proper solutions aimed at solving these children's issues and making their parents aware of the adverse effects of employing inappropriate parenting styles on the incidence of emotional disorders among children can aid these children to improve their conditions. Accordingly, the present study was conducted with the aim of comparing graphic characteristics of drawing a family, attachment disorders, and parental parenting styles in anxious and normal girl children.

\section{Method}

The method of this study was casualcomparative. In the current study, the independent variables are two groups of anxious and normal children and the dependent variables are graphical characteristics of drawing a family, attachment disorders, and parental parenting styles. The statistical population included all 5 to 8 years old children studying in kindergartens and elementary schools of Zahedan, Iran, in 2015-2016 academic years 6 and their parents. Among these children, 100 children ( 50 normal children and 50 children with anxiety disorders) were randomly selected as the sample. All ethical considerations including confidentiality of the obtained data and subjects' eagerness to take part in this study were observed. In the present study, the data collection tools were the DAF test, the Randolph Attachment Disorder Questionnaire (RADQ), and the Baumrind Parenting Style Test. The former test was conducted on the children and the latter two inventories were carried out on their parents. 
The data were analyzed by using the chi-square and MANOVA via SPSS- 16.

The DAF test was initially designed by Dapel and Wolf; however, later Hulse developed it fully. In addition to individual characteristics of a subject, the DAF test reflects his/her family relations and needs. In the present study, extroverted tendencies, introverted tendencies, worthiness, unworthiness, the type of drawing (intellectual and sensational), and depression were all considered in accordance with the criteria related to the DAF test provided in children's drawing books including Application of the DAF test and evaluation of Children's Characters Based on the drawing tests. accordingly, when examining the children's drawings, the score of 1 is considered for each detected symptom related to the considered subscales and the score of 0 is regarded in the absence of such symptoms. The validity of the obtained results of this test is highly dependent on a therapist's clinical experiences. Cormen conducted a study on a sample of 1200 children aged 6 to 14 years old ( 800 boys and 400 girls) and concluded that this test can distinguish normal states from specific or distortionary states [26]. In Iran, the validity of the DAF Test examined in a sample of 100 children was 0.84 . With regard to the validity of various methods of scoring, the concurrent validity, and the sensitivity to changes in clinical states, different studies obtained various results [27].

The RADQ was designed in America in 2000 to introduce attachment disorders. This is a 30item checklist which should be completed by parents or caregivers of a child and examines several problems that were observed by the parents or caregivers during the last two years [28]. After performing the exploratory factor analysis, Movahed Abtahi, Amiri, and Amsaki [4] determined three distinct factors named bullying, impulsivity, and antisocial behaviors. After indicating these three factors, the statistical indicators of this questionnaire were reassessed. Since their load factors were less than 0.3 , questions $17,25,26,27$, and 30 were eliminated from the questionnaire. Therefore, this questionnaire was changed into a 25-item questionnaire with a cut-off point of 30. This questionnaire introduces and detects attachment disorders among children aged 5 to 18 years old. The internal consistency of the RADQ was assessed by using the odd-even method, such that the correlations between all odd scores and all even scores were calculated. This method was carried out on 80 participants with attachment disorders and 35 participants with a history of abnormal behaviors who did not suffer from any attachment disorders. The obtained results indicated that the correlation coefficients for participants with attachment disorders and the other group were respectively 0.84 and 0.81 . These results confirmed the good internal consistency of this questionnaire. The validity of the Randolph Attachment Disorder [29] was tested using various methods. The test-retest reliability of this questionnaire examined among 70 children (40 children with attachment disorders and 30 children without any psychiatric issues) ranged from 0.82 to 0.85 . The internal stability of this questionnaire was 0.84 that is desirable. In the original method of scoring, scores ranging from 65 to 75 indicate mild attachment disorders, scores ranging from 76 to 89 shows moderate attachment disorders, and scores higher than 90 demonstrate severe attachment disorders. The standardization of the Persian version was conducted in a study carried out by Movahed Abtahi, Amiri, and Amsaki on 340 students aged 7 to 12 years old studying at schools in Isfahan [4]. The parents of the participants completed the RADQ. Based on the obtained data, the score of 30 was offered as the best cut-off point. This cut-off point corresponded with the $60 \%$ point. The face validity and construct validity of this questionnaire were confirmed by the specialists. Additionally, using the Cronbach's alpha coefficient, the diagnostic validity of its subscales was 0.83 . Given the results obtained from other studies, it can be mentioned that this is a reliable and valid questionnaire that can be used to examine attachment disorders. Furthermore, this questionnaire is scored based on a 5-point Likert-type scale ranging 
from 1 (never) to 5 (always) [4].

The Baumrind Parenting Style Test was developed in 1972. It includes 30 items. Every 10 questions examine a type of parenting style. In this regard, it evaluates three parenting styles including the authoritative, authoritarian, and permissive styles. This test is scored based on a 5-point Likert-type scale ranging from 0 (totally disagree) to 5 (totally agree). Using the test-retest method, Baumrind examined the reliability of this test among a group of mothers and reported that the reliability of the authoritative, authoritarian, and permissive parenting styles was respectively $0.86,0.88$, and 0.81 . The Persian version of this test was standardized in a study carried out by Esfandiari [30]. By using the test-retest reliability, Esfandiari reported that the reliability of the authoritarian, authoritative, and permissive parenting styles was respectively $0.77,0.73$, and 0.69 [30]. The reliability of the authoritarian, authoritative, and permissive parenting styles examined by using the test-retest reliability was respectively $0.85,0.92$, and 0.81 .

\section{Results}

To compare the demographic characteristics of drawing a family in anxious and normal children, the characteristics of drawn people (a parent, a sister, a brother, the subject himself/herself, and others) were examined. The results of this study show significant differences between the anxious and normal children with regard to the frequency of the observed and expected cases related to worthiness which represents a child's very significant relationships with the worthful person and his/her emotional investment on the person. The characteristics related to worthiness include the first drawing $\left(x^{2}=9.091, p=0.003\right)$, drawing the person taller than others $\left(\mathrm{x}^{2}=11.791\right.$, $\mathrm{p}=0.001)$, drawing complete lines $\left(\mathrm{x}^{2}=14.446\right.$, $\mathrm{p}=0.0005)$, decorating the person $\left(\mathrm{x}^{2}=5.191\right.$, $p=0.0002$ ), and focusing all the attention on that person $\left(\mathrm{x}^{2}=4.937, \mathrm{p}=0.02\right)$.

Moreover, significant differences are found between the anxious and normal children considering the frequency of the observed and expected cases related to unworthiness including drawing small people $\left(\mathrm{x}^{2}=11.565, \mathrm{p}=0.001\right)$, drawing people with a distant $\left(\mathrm{x}^{2}=4.167\right.$, $\mathrm{p}=0.04)$, and not regarding any values for people $\left(\mathrm{x}^{2}=5.567, \mathrm{p}=0.01\right)$; however, no significant differences are found with regard to drawing on the margins $\left(\mathrm{x}^{2}=1.086, \mathrm{p}=0.29\right)$, not drawing any details $\left(\mathrm{x}^{2}=1.980, \mathrm{p}=0.15\right)$, and lack of replication $\left(\mathrm{x}^{2}=1.507, \mathrm{p}=0.22\right)$. In addition, the results of indicate that there is not any significant difference between the anxious and normal children with regard to the frequency of the observed and expected cases related to the feelings of discrimination and difference in children towards their parents' behaviors including getting rid of the rival $\left(\mathrm{x}^{2}=3.330, \mathrm{p}=0.06\right)$; however, statistically significant differences are found between the anxious and normal children with regard to the frequency of the observed and expected cases related to relations with distance $\left(x^{2}=13.30\right.$, $\mathrm{p}=0.002)$ and devaluing the rival $\left(\mathrm{x}^{2}=14.66\right.$, $\mathrm{p}=0.0005$ ).

Furthermore, there are statistically significant differences between the anxious and normal children with regard to the frequency of the observed and expected cases related to sensational drawing, which represents the warm atmosphere in the family and the dynamics of relationships between family members, including sensational and lively atmosphere $\left(\mathrm{x}^{2}=5.741, \mathrm{p}=0.001\right)$ and drawing curved line $\left(x^{2}=10.714, p=0.001\right)$. Moreover, there are statistically significant differences between the anxious and normal children with regard to the frequency of the observed and expected cases related to intellectual drawing, which represents the lack of warmth and dynamics in the relationships between family members, including drawing repetitive and static people $\left(x^{2}=6.775, p=0.009\right)$ and drawing angled line $\left(x^{2}=10.714, p=0.0001\right)$. In addition, there are statistically significant differences between the anxious and normal children with regard to the frequency of the observed and expected cases related to depression including self-removal $\left(\mathrm{x}^{2}=5.198\right.$, $\mathrm{p}=0.02)$, self-criticism $\left(\mathrm{x}^{2}=4.167, \mathrm{p}=0.04\right)$, and self-unworthiness $\left(x^{2}=9.091, p=0.003\right)$. 
However, there are not any statistically significant differences between the anxious and normal children with regard to the frequency of the observed and expected cases related to lack of safety $\left(x^{2}=0.160, p=0.68\right)$, fear $\left(x^{2}=0.160\right.$, $\mathrm{p}=0.68)$, and regression reactions $\left(\mathrm{x}^{2}=2.667\right.$, $\mathrm{p}=0.10)$.

Additionally, there is a statistically significant difference between the anxious and normal children with regard to the frequency of the observed and expected cases related to extroverted tendencies which represent crucial developments to have life expectancy and positive attitudes towards life $\left(\mathrm{x}^{2}=4.889\right.$, $\mathrm{p}=0.02$ ) and there is a statistically significant difference between the anxious and normal children with regard to the frequency of the observed and expected cases related to introverted tendencies which represent the lack of such developments $\left(\mathrm{x}^{2}=4.058, \mathrm{p}=0.04\right)$.

Table 1 Descriptive results related to attachment disorders and parenting styles in the two groups of normal and anxious children

\begin{tabular}{llcccc}
\hline & \multicolumn{2}{c}{ Variables } & \multicolumn{2}{c}{ Normal children } & \multicolumn{2}{c}{ Anxious children } \\
\hline \multirow{3}{*}{$\begin{array}{l}\text { Attachment } \\
\text { disorders }\end{array}$} & Mean & SD & Mean & SD \\
\cline { 2 - 6 } & Bullying & 14.093 & 5.05 & 17.00 & 5.89 \\
& Antisocial behaviors & 11.67 & 3.87 & 12.64 & 3.63 \\
& Impulsivity & 11.06 & 3.06 & 12.14 & 4.44 \\
\hline \multirow{3}{*}{ Parenting styles } & Permissive & 15.46 & 5.42 & 16.09 & 3.63 \\
& Authoritarian & 16.12 & 3.87 & 18.07 & 3.63 \\
& Authoritative & 32.67 & 4.15 & 31.72 & 4.37 \\
\hline
\end{tabular}

According to the above table, it can be inferred that the anxious children obtained the highest mean on bullying which was considered as a dimension of attachment disorders (M:14.93, SD:5.05). Moreover, considering the parenting styles, the anxious children, compared to the normal children, obtained higher means on the permissive parent style $(\mathrm{M}=18.07$, $\mathrm{SD}=3.63$ ) and the authoritarian parenting style $(\mathrm{M}=16.09, \mathrm{SD}=3.63)$. However, with regard to the authoritative parenting style, the normal children, compared to the anxious children, obtained a higher mean $(\mathrm{M}=32.67$, $\mathrm{SD}=4.15)($ Table 1).

Table 2 Results of the kolmogorov-smirnov test and the levene's test

\begin{tabular}{|c|c|c|c|c|c|c|c|}
\hline \multirow{2}{*}{\multicolumn{2}{|c|}{ Variables }} & \multirow{2}{*}{$\begin{array}{l}\text { Statistic of } \\
\text { the Levene's } \\
\text { test }\end{array}$} & \multirow[b]{2}{*}{ df1 } & \multirow[b]{2}{*}{$\mathrm{df} 2$} & \multirow[b]{2}{*}{ sig. } & \multicolumn{2}{|c|}{ Kolmogorov-Smirnov test } \\
\hline & & & & & & Kolmogorov-Smirnov & $\operatorname{sig}$ \\
\hline \multirow{3}{*}{ Attachment disorder } & Bullying & 0.77 & 1 & 98 & 0.38 & \multirow{3}{*}{1.148} & \multirow{3}{*}{0.144} \\
\hline & Antisocial behaviors & 0.16 & 1 & 98 & 0.68 & & \\
\hline & Impulsivity & 2.91 & 1 & 98 & 0.09 & & \\
\hline \multirow{3}{*}{ Parenting styles } & Permissive & 5.82 & 1 & 98 & 0.11 & \multirow{3}{*}{0.634} & \multirow{3}{*}{0.817} \\
\hline & Authoritarian & 1.21 & 1 & 98 & 0.27 & & \\
\hline & Authoritative & 0.002 & 1 & 98 & 0.96 & & \\
\hline
\end{tabular}

The one-sample Kolmogorov-Smirnov test was carried out to determine the normality of the data before analyzing the data and conducting the multivariate analysis of variance. The results showed that the levels of significance obtained from the normality test were greater than 0.05 ; therefore, the variables of attachment disorder and parenting styles followed normal distributions. Moreover, to investigate the assumption of homogeneity of variances, the Levene's test was applied. The obtained results was presented in Table 1 that indicated that since the levels of significance of all the subscales were greater than 0.05 , the assumption of homogeneity of variances was not violated (Table 2).

The Lambda statistical index used in the multivariate analysis of variance to examine 
attachment disorders indicates that there are not any statistically significant differences between these two groups in terms of attachment disorders $(\mathrm{F}=2.4234$, Wilks' Lambda $=0.930$, $\mathrm{p}=0.07)$. However, assessing the mean scores of the normal and anxious children shows a statistically significant difference between these two groups with regard to the subscale of bullying $(p=0.009)$. Therefore, the null hypothesis, assuming that the mean scores of the normal and anxious children on the subscale of bullying are equal, is rejected at the $99 \%$ confidence level. The effect size calculated using the eta squared is 0.67 which is classified as a large effect size. However, considering the other two subscales, i.e. antisocial behaviors and impulsivity, no significant differences are found between these two groups at the $\mathrm{p}<0.19$ and $\mathrm{p}<0.15$ respectively (Table 3).

Table 3 The results of the multivariate analysis of variance (MANOVA) was conducted to examine three subscales of bullying, antisocial behaviors, and impulsivity in both groups

\begin{tabular}{lcccccc}
\hline Variable & $\begin{array}{c}\text { Sum of } \\
\text { squares }\end{array}$ & df & $\begin{array}{c}\text { Mean of } \\
\text { squares }\end{array}$ & F & Eta & Sig \\
\hline Bullying & 212.412 & 1 & 212.412 & 7.039 & 0.67 & 0.009 \\
Antisocial behaviors & 23.645 & 1 & 23.645 & 1.676 & 0.01 & 0.19 \\
Impulsivity & 29.361 & 1 & 29.361 & 2.017 & 0.02 & 0.15 \\
\hline
\end{tabular}

The Lambda statistical index was used in the multivariate analysis of variance to examine parenting styles that shows there are not any statistically significant differences between these two groups in terms of parenting styles $(\mathrm{F}=1.244$, Wilks' Lambda=0.963, $\mathrm{p}=0.29)$. Moreover, assessing the mean scores of the normal and anxious children shows that there are not any statistically significant differences between these two groups with regard to the permissive, authoritarian, and authoritative parenting styles respectively at the $p>0.49$, $\mathrm{p}>0.10, \quad \mathrm{p}>0.26$. Therefore, the null hypothesis, assuming that the mean scores of the normal and anxious children on the permissive, authoritarian, and authoritative parenting styles are alike, is confirmed (Table 4).

Table 4 The results of the multivariate analysis of variance (MANOVA) conducted to examine the parenting styles in both groups

\begin{tabular}{lcccccc}
\hline Variable & Sum of squares & df & Mean of squares & F & Eta & Sig \\
\hline Permissive & 9.86 & 1 & 9.86 & 0.46 & 0.005 & 0.49 \\
\hline Authoritarian & 94.83 & 1 & 94.83 & 2.65 & 0.026 & 0.10 \\
\hline Authoritative & 22.69 & 1 & 22.69 & 1.24 & 0.013 & 0.26 \\
\hline
\end{tabular}

\section{Discussion}

As the results demonstrated, there were significant differences between the normal and anxious groups with regard to the graphic characteristics of drawing a family including worthiness, discrimination and difference in the family, drawing sensational and intellectual shapes, and extroverted and introverted tendencies. These findings are consistent with the results of Olweus [31], Burkitt, Barret, and Davis [32], and Moradi, Eskandari, and Borjali [33] that indicated the statistically significant differences in the mentioned characteristics. Considering unworthiness which represents itself through drawing small people, drawing people with a considerable distant, and devaluing people, there were significant differences between these two groups. These findings are consistent with the results of Gari [34] that showed a statistically significant difference in the mentioned characteristics between normal and children with unfavorable conditions. However, in terms of drawing on the margins, not drawing the details, and lack of replication, there were not any significant differences between these two groups. 
Moreover, there were significant differences between these two groups considering some characteristics related to depression including self-removal, self-criticism, and selfunworthiness. These findings are in line with the results of studies carried out by Moradi, Eskandari, and Borjali [33] and Einbender and Friedrich [35] that revealed statistically significant differences in the mentioned characteristics. However, no significant difference was found between these two groups considering the other symptoms of depression including the lack of safety, fear, and regression reactions.

Accordingly, given the results obtained from the current study, it can be inferred that drawing a family is a proper method to detect family and emotional issues and a family can be considered as the most effective factor that affects children's drawings. Since anxious children display a kind of attentional bias towards threatening stimuli and they perceive the surrounding world in a different way, they have to deal with more negative consequences when facing stressful events. This, on its own, affects all aspects of their lives [36]. All these are important abnormalities which certainly threaten a child's mental health and disrupt his/her normal life and natural evolution [27]. Additionally, in this study, there was a significant difference between these two groups with regard to bullying, a subscale of attachment disorders; however, considering the other two subscales, i.e. antisocial behaviors and impulsivity, no significant difference was found between these two groups. This indicates that since children with the bullying disorder do not experience their parents' empathy and have been rejected by their parents, they use immature defensive mechanisms; therefore, when dealing with their issues, they show high levels of aggression, hostility, and/or isolation. They apply bullying as a method to attract others' attention [37]. Furthermore, bullying indicates a special form of aggressive behaviors in these children [38].

In the current study, no significant difference was found between these two groups with regard to the subscales of parenting styles. This finding is consistent with the results of Davarifard and Emami [39], Gorji and Mahmoudi [40].To explain this finding, it can be stated that since the parental parenting styles are assessed based on people's retrospective reports, there is a possibility that people report their current situations and parenting styles and this aids people to not feel any shortages compared to others ]39[. In addition, in this study, the subjects' scores on the authoritative parenting style were higher than their scores on the other two parenting styles. This may be due to the fact that parents have become aware of various parenting styles and many of them tend to apply the authoritative and democratic parenting styles [40].

Among the limitations of the current study, the difficulties of working with children and the fact that conducting the DrawAFamily Test is really time-consuming can be mentioned. Therefore, examining some confounding factors other than family including environmental factors associated with children's anxiety disorders is suggested. Moreover, through holding committees including developmental, educational, and clinical psychologists, administrative and governmental agencies can train teachers, school counselors, and parents (employed and unemployed) to become aware of the methods of establishing relationships and interactions with children and aiding children to build emotional security

\section{Conclusion}

The results indicated statistically significant differences between the normal and anxious groups in the graphical characteristics of drawing a family. Moreover, considering the subscales of attachment disorders, there was a significant difference between these two groups in terms of bullying. However, no significant difference was found between these two groups with regard to the parenting styles. Overall, given the results obtained from this study and other studies, it can 
be stated that interactions within a family, relationships between parents, parentschildren relations, and relationships between children play key roles in the formation of a child's character, peace of mind, sense of safety, self-confidence, and consistency and they affect the incidence of proper behaviors and protect a child from mental disorders.

\section{Acknowledgment}

The authors would like to thank all the people who helped them to conduct this study.

\section{Authors' contributions}

Study Design: MS,MR,HS

Data collection and analysis:HS

Manuscript preparation: HS

All authors have read and approved the final version.

\section{Conflict of Interest}

"The authors declare that they have no competing interests."

\section{Funding}

The authors received no financial support for the research, authorship and/or publication of this article.

\section{Availability of data and materials}

The datasets used and/or analyzed during this study are available from the corresponding author on reasonable request.

\section{Reference}

1- Asli Azad M, Arefi M, Farhadi T, Sheikhmohammadi RA. The effectiveness of child-centered play therapy on anxiety and depression among female elementary school children with anxiety and depression disorders. Journal of Psychological Methods and Models2012; 2(9): 71-90.

2- Dadsetan P. Developmental psychopathology from childhood to adulthood. Tehran: Nasher publication; 2014. 3- Burke L. Lifelong developmental psychology- from 0 years old to teenagers. Translated by: Seyyed Mohammadi Y. Tehran: Arasbaran publication; 2007.

4-Movahed Abtahi M, Amiri S, Emsaki G. Standardization and study of the psychometric properties of randolph attachment disorder questionnaire. Journal of Knowledge and Research in Applied Psychology2012; 13(49): 46-55. 5- Jahanbakhsh M, Amiri SH, Molavi H, Bahadori MH.
The relationship of the attachment problems of girls with the attachment style of mothers. Journal of Clinical Psychology2011; 3(7): 15-24.

6- Gimpel GA, Holland ML. Emotional and behavioral problems of young children: Effective interventions in the preschool and kindergarten years. New York: Guilford press; 2003.

7- Saduk BJ, Saduk VA. Kaplan \& sadock's pocket handbook of clinical psychiatry. 3rd edition. Translated by: Arjman M, Rezaee F, Faghani Jadidi N. With an introduction written by: Jalili A. Tehran: Ketab-eArjmand publication; 2003.

8- Kamijani M. Reactive attachment disorder. Journal of Exceptional Education2000; 2(109): 22-62.

9- Atkinson RL, Atkinson RC, Hilgard ER. Introduction to psychology. 8th Edition. California: Harcourt Brace Javanovich; 1983.

10- Faramarzi S, Taghipoorjavan AA, Dehghani M, Moradi M. Comparison of attachment styles and child rearing in parenting mothers of normal students and students with learning disabilitie. Jentashapir Journal2013; 4(3): 245-54.

11- Rahmani P, Naimeh M. Examining parenting styles and emotional atmosphere of family among children with and without generalized anxiety disorder. Journal of Educational Sciences2011; 4(13): 67-78.

12- Shokouhi Y, Parand A, Faghihi AN. A comparative study of parenting styles. Islamic Training2006; 2(3): 115-40.

13- Alavi M. Family and education. Tehran: Amiri publication; 2005.

14- Chery B. Interaction between parents and children. Translated by: Dehghanpour M, Farazchi M. Tehran: Roshd publication; 1998.

15- Mojganian D. The relationship between parents' parenting styles and identity statuses among teenage female high school students in district four of Tehran. [dissertation]. Tehran: Islamic Azad University, Science and Research Branch 2001. pp: 108.

16- Zahedian SF, Mohammadi M, Samani S. The role of attachment styles, parental bonding, and self-concept in sexual addiction. Clin Psychol2011; 3(3): 65-73.

17- Dadsetan P. Evaluation of children's character based on graphical tests. 7th edition. Tehran: Roshd publication; 2012.

18- Shakerian A. Comparing draw-a-family to conduct psychological analysis on children in normal and single parent families. Journal of Mental Health Principles2009; 11(4): 312-21.

19- Bahrami H. Clinical and diagnostic application of character projection tests. Tehran: Dana publication; 1993.

20- Iravani M, Valizadeh Sh, Shfifardi I. A comparison of graphical indices of children with discrete and 
indiscrete in the Draw-A-Family Test. Quarterly of Applied Psychology2007; 2(5): 9-22.

21. Dadsetan P. Evaluation of children's character based on graphical tests. 7th edition. Tehran: Roshd publication; 2012.

22- Vazirnia S, Ganji T. Child's drawing: growth, features, issues, application. Tehran: Qatreh publication; 2001.

23- Thomas G, Silk V, Angel MJ. Introduction to psychology of children's drawing. Translated by: Mokhbar A. Tehran: Tarh-e-No publication; 1990.

24- Khanjani Z, Hashemi T, Elhamfar F. Examining the relationship of parenting styles and attachment styles with symptoms of depression in adolescents. Journal of Educational Sciences2011; 4(14): 91-106.

25- Peivastegar M, Seif S, Darvizeh Z, Pourshahriari S. Predicting attachment disorder among elementary school children based on their parents' attachment style. Journal of Psychological Studies2006; 2(1): 125-46.

26- Cormen L. Draw-A-Family test in the clinic. Translated by: Dadsetan P, Mansour M. 7th edition. Tehran: Roshd publication; 2012.

27- Khodayarifard S, Abedini A, Yekeyazdandoost R, Shahriari MS, Gharraee B. Comparing the results of projective drawing in children who have been physically abused and normal children. Journal of Family Research2007; 3(9): 455-69.

28- Morgan PS. Frequency of RAD diagnosis and attachment disorder in community mental health agency clients [dissertation]. Kentucky: University of Louisville 2004. pp: 143.

29- Moorer KS. Recognizing reactive attachment disorder in foster children. [dissertation]. Minneapolis, MN: Capella university 2007. pp: 372.

30- Esfandiari Gh. Study and comparison of parenting styles of mothers of children with behavioral disorders and mothers of normal children and effect of mothers training on children behavioral disorders. [dissertation]. Tehran: Tehran Institute of Psychiatry 1995. pp: 147.

31. Olweus D. Aggression in the schools: Bullies and whipping Boys. Washington, DC: Hemisphere (Wiley); 1983.

32- Burkitt E, Barret M, Davis A. The effect of affective characterizations on the use of size and color in drawings produced by children in the absence of a model. Educ Psychol2004; 24(3): 315-43.

33- Moradi K, Eskandari H, Borjali A. Features of Draw-a-person and draw-a-family tests among children with ADHD and normal children. Journal of School Counseling2007; 3(1): 46-53.

34- Gari GM. Handbook of psychology test. Translated by: Sharifi HP. Tehran: Roshed publication; 1990.

35- Einbender AJ, Friedrich WN. Psychological functioning and behavior of sexually abused girls. $J$ Consult Clin Psychol1989; 57(1): 155-7.

36- Mofrad S, Atef V, Mohammed K, Bayanzadeh SA. Comparing the concerns of anxious and ordinary children in Dashtestan. Iranian Journal of Psychiatry and Clinical Psychology2002; 8(2): 65-72.

37- Ghomrigio H, Soroushzadeh SH, Nader M, Mikaeeli N. Effects of olweus bullying prevention program on elementary-school students' social skills and selfesteem. Clinical Psychology and Personality2013; 3(11): 49-75.

38- Pourseyedi SR, Amiri Sh, Molavi H, Pourseyyed SM. The effectiveness of maternal training program on the level of bullying among fifth grade elementary school students. Journal of Social Psychology (New Findings in Psychology)2012; 7(24): 131-43.

39- Davarifard F, Mami S. Comparison of personality characteristics and parenting styles among mothers of female elementary school students with externalizing disorder and mothers of normal students in Ilam. Scientific Journal of Ilam Medical University of medical sciences2015; 23(2): 149-58.

40- Gorji R, Mahmoudi A. The comparison between parenting styles and general health in parents who had deaf and mentally-retarded children. Exceptional Education2013; 5(113): 15-24.

\footnotetext{
Copyright(C) 2016 ASP Ins. This open-access article is published under the terms of the Creative Commons Attribution-NonCommercial 4.0 International License which permits Share (copy and redistribute the material in any medium or format) and Adapt (remix, transform, and build upon the material) under the Attribution-NonCommercial terms.
} 